\title{
A comparison of ground-based hydroxyl airglow temperatures with SABER/TIMED measurements over $23^{\circ} \mathrm{N}$, India
}

\author{
Navin Parihar ${ }^{1}$, Dupinder Singh ${ }^{2}$, and Subramanian Gurubaran ${ }^{2}$ \\ ${ }^{1}$ Equatorial Geophysical Research Laboratory, Indian Institute of Geomagnetism, Tirunelveli 627 011, India \\ ${ }^{2}$ Indian Institute of Geomagnetism, Navi Mumbai 410 218, India \\ Correspondence to: Navin Parihar (navindeparihar@gmail.com)
}

Received: 18 October 2016 - Revised: 3 February 2017 - Accepted: 8 February 2017 - Published: 7 March 2017

\begin{abstract}
Ground-based observations of $\mathrm{OH}(6,2)$ Meinel band nightglow were carried out at Ranchi $\left(23.3^{\circ} \mathrm{N}\right.$, $85.3^{\circ} \mathrm{E}$ ), India, during January-March 2011, December 2011-May 2012 and December 2012-March 2013 using an all-sky imaging system. Near the mesopause, $\mathrm{OH}$ temperatures were derived from the $\mathrm{OH}(6,2)$ Meinel band intensity information. A limited comparison of $\mathrm{OH}$ temperatures $\left(T_{\mathrm{OH}}\right)$ with SABER/TIMED measurements in 30 cases was performed by defining almost coincident criterion of $\pm 1.5^{\circ}$ latitude-longitude and \pm 3 min of the ground-based observations. Using SABER OH 1.6 and $2.0 \mu \mathrm{m}$ volume emission rate profiles as the weighing function, two sets of $\mathrm{OH}-$ equivalent temperature ( $T_{1.6}$ and $T_{2.0}$ respectively) were estimated from its kinetic temperature profile for comparison with $\mathrm{OH}$ nightglow measurements. Overall, fair agreement existed between ground-based and SABER measurements in the majority of events within the limits of experimental errors. Overall, the mean value of OH-derived temperatures and SABER OH-equivalent temperatures were $197.3 \pm 4.6$, $192.0 \pm 10.8$ and $192.7 \pm 10.3 \mathrm{~K}$, and the ground-based temperatures were $4-5 \mathrm{~K}$ warmer than SABER values. A difference of $8 \mathrm{~K}$ or more is noted between two measurements when the peak of the $\mathrm{OH}$ emission layer lies in the vicinity of large temperature inversions. A comparison of $\mathrm{OH}$ temperatures derived using different sets of Einstein transition probabilities and SABER measurements was also performed; however, OH temperatures derived using Langhoff et al. (1986) transition probabilities were found to compare well.
\end{abstract}

Keywords. Atmospheric composition and structure (airglow and aurora; instruments and techniques)

\section{Introduction}

The mesosphere-lower thermosphere (MLT) region (80$105 \mathrm{~km}$ ) of the earth's atmosphere is a complex system that is strongly controlled by several physical processes from above and by dynamical processes from below. Its thermal structure is influenced by the absorption of incident solar radiation, auroral heating by currents and particles, solar and secondary energetic particles, incoming cosmic flux, and infrared radiative cooling due to $\mathrm{CO}_{2}$. The dynamical forcings (viz. gravity waves, tides and planetary waves) and the anthropogenic changes due to human activity together with the lower atmosphere strongly influence its thermal structure as well (Brasseur and Solomon, 1984; Mlynczak and Solomon, 1993; Mlynczak, 1997; Smith, 2004). Owing to this, knowledge of temperature of the MLT region is one of the crucial parameters in understanding its structure and dynamics.

Nightglow observations of $\mathrm{OH}$ Meinel band have been widely used to obtain the temperature information of the upper mesospheric region near $87 \pm 4 \mathrm{~km}$ (Meriwether, 1975; Offermann and Gerndt, 1990; Scheer and Reisin, 1990; Takahashi et al., 1994; Greet et al., 1998; French et al., 2000; Bittner et al., 2002; Burns et al., 2003; Mukherjee and Parihar, 2004; Offermann et al., 2010; Parihar et al., 2013). Several space-borne instruments like the Microwave Limb Sounder (MLS) on the Aura satellite; Atmospheric Chemistry Experiment - Fourier Transform Spectrometer (ACE-FTS) on SciSat-1; Michelson Interferometer for Passive Atmospheric Sounding (MIPAS) and SCIAMACHY (Scanning Imaging Absorption Spectrometer for Atmospheric Chartography) on Environmental Satellite (ENVISAT); Solar Occultation for Ice Experiment (SOFIE) on the AIM satellite; Optical, Spectroscopic, and Infrared Remote Imaging System (ORISIS) on the Odin satellite; the Cryogenic Infrared Spectrometers 
and Telescopes for the Atmosphere (CRISTA) satellite instrument, and Sounding of the Atmosphere by Broadband Emission of Radiation (SABER) on-board the TIMED mission satellite have also contributed immensely to our knowledge of the temperature field of the MLT region (von Savigny et al., 2004; Scheer et al., 2006; Xu et al., 2007; Mulligan and Lowe, 2008; French and Mulligan, 2010; Sheese et al., 2011; García-Comas et al., 2012, 2014; and references cited therein).

Although the ground-based observations provide invaluable information on the local time domain and have tremendous capability for long-term operation with costeffectiveness, they alone are probably not enough to resolve critical issues being globally restricted by landmass distribution. Conversely, the space-borne measurements are unable to provide local information. As such, the coordinated use of similar geophysical datasets is needed to obtain a better understanding of the MLT region (especially to explore seasonal geographical variations and long-term trends). Several investigators have reported the comparative study of the ground-based $\mathrm{OH}$ temperatures and satellite-borne measurements. Von Savigny et al. (2004) first reported nearglobal satellite-borne measurements of $\mathrm{OH}(3,1)$ Meinel band temperatures performed with the SCIAMACHY instrument. A comparison of these temperatures with the groundbased $\mathrm{OH}$ temperatures at Maui, Hawaii $\left(21^{\circ} \mathrm{N}\right)$, Hohenpeißenberg $\left(47^{\circ} \mathrm{N}\right)$ and Wuppertal $\left(51^{\circ} \mathrm{N}\right)$ indicated that the two sets of measurements are in good agreement with each other, with the mean difference being 7.1, 2.6 and $2.7 \mathrm{~K}$ respectively. At Wuppertal $\left(51^{\circ} \mathrm{N}\right)$, Oberheide et al. (2006) found $\mathrm{OH}(3,1)$ temperatures to be systematically warmer than the SABER measurement (on average by $7.5 \mathrm{~K}$ ) during 2003-2005. Using the mesopause region temperature measurements by the CRISTA- 1 and CRISTA- 2 missions, Scheer et al. (2006) performed such a comparison of groundbased $\mathrm{OH}$ temperature measurements at eight sites (spread over $38-63^{\circ} \mathrm{N}$ and $32-69^{\circ} \mathrm{S}$ ). López-González et al. (2007) reported the measurements of $\mathrm{OH}(6,2)$ Meinel band and $\mathrm{O}_{2}(0,1)$ atmospheric band temperatures with Spectral Airglow Temperature Imager (SATI) at the Sierra Nevada Observatory $\left(37^{\circ} \mathrm{N}\right)$ and their comparison with SABER observations. These authors noted (i) a similar night-to-night as well as seasonal variation of the temperatures from the two datasets, (ii) SABER temperatures to be colder than SATI measurements by $\sim 5.7 \mathrm{~K}$ at $87 \mathrm{~km}$ and (iii) SATI temperatures to be colder than SABER measurements by $\sim 2.5 \mathrm{~K}$ at $95 \mathrm{~km}$. Mulligan and Lowe (2008) performed a comparison of $\mathrm{OH}(3,1)$ temperatures with ACE-FTS and SABER measurements at three airglow stations - Wuppertal $\left(51^{\circ} \mathrm{N}\right)$, Maynooth $\left(53.2^{\circ} \mathrm{N}\right)$ and Stockholm $\left(59.5^{\circ} \mathrm{N}\right)$. These authors found (i) $\mathrm{OH}$ equivalent temperatures derived from ACEFTS to be in good agreement with SABER observations and (ii) $\mathrm{OH}$ temperatures to be warmer than satellite measurements in the 4.5-8.6 K range. French and Mulligan (2010) presented an extensive comparison of $\mathrm{OH}(6,2)$ temperature measurements at Davis $\left(68^{\circ} \mathrm{S}\right)$, Antarctica, with Aura-MLS and SABER measurements during 2004-2009 and 20022009 respectively. These authors observed an annual increasing trend $\left(\sim 0.7 \mathrm{~K}_{\text {year }}{ }^{-1}\right)$ in warm bias between $\mathrm{OH}$ temperatures and SABER measurements and an opposite constant bias of $\sim 10 \mathrm{~K}$ between $\mathrm{OH}$ temperature and AuraMLS observations. Sheese et al. (2011) compared $\mathrm{O}_{2}$ temperature measurements using the ORISIS instrument with SABER and SOFIE values. These authors found ORISIS temperatures to be lower than SABER and SOFIE measurements. Overall, these studies indicate a warm bias between the ground-based $\mathrm{OH}$ temperatures and the satellite measurements. Such comparisons serve as a means of identifying biases between the two measurement methods and substantiating their combined use in understanding the MLT thermal structure.

In the present study, a limited comparison of almost coincident measurements of the ground-based $\mathrm{OH}(6,2)$ temperatures and SABER observations was performed at a lowlatitude station in Ranchi $\left(23^{\circ} \mathrm{N}\right)$, India, using a strict spatial and temporal coincidence criterion of $\pm 1.5^{\circ}$ latitudelongitude and $\pm 3 \mathrm{~min}$. As $\mathrm{OH}$ temperature represents the weighted temperature of $\mathrm{OH}$ emission layer, first the $\mathrm{OH}-$ equivalent temperatures was estimated from the SABER kinetic temperature profiles and then a comparison was made with ground-based airglow temperatures. Using different sets of Einstein transition probabilities, $\mathrm{OH}$ temperatures were derived and a comparison was performed so as to identify the closest matching set of transition probabilities for $\mathrm{OH}$ temperature measurements.

\section{Ground-based instrumentation and $\mathrm{OH}$ temperature data}

Using a charge-coupled device (CCD)-based all-sky imaging system (developed by Keo Scientific Ltd., Canada), groundbased monitoring of $P_{1}(2)$ and $P_{1}(4)$ lines of $\mathrm{OH}(6,2)$ Meinel band at 839.92 and $846.52 \mathrm{~nm}$ respectively was carried out in Ranchi $\left(23.3^{\circ} \mathrm{N}, 85.3^{\circ} \mathrm{E}\right)$, India. Monitoring of the background emission at $857.0 \mathrm{~nm}$ was also carried out. This imager is an $f / 4$ imaging system consisting of (i) a Mamiya fisheye lens of $\sim 180^{\circ}$ field of view, (ii) a sixfilter wheel unit and imaging optical assembly and (iii) a $512 \times 512$ pixel back-illuminated CCD detector (Princeton Instruments PIXIS 512B, imaging area $13.3 \mathrm{~mm} \times 13.3 \mathrm{~mm}$, and single-pixel area $24 \times 24 \mu \mathrm{m}^{2}$ ). The filter wheel unit and CCD detector are thermoelectrically maintained at 25 and $-80{ }^{\circ} \mathrm{C}$ respectively. Around $825 \mathrm{~nm}$, the quantum efficiency of the CCD detector is 70-80\% and the dark current is less than $0.001 \mathrm{e}^{-}$pixel $^{-1} \mathrm{~s}^{-1}$. Parihar and Taori (2015) described this imaging system in detail. Optical filters for monitoring $P_{1}(2)$ line and $P_{1}(4)$ line had a bandwidth of $\sim 1.1 \mathrm{~nm}$, while that of the $857.0 \mathrm{~nm}$ filter was $\sim 2.0 \mathrm{~nm}$. The transparency of these filters is in the range of $77-$ 
Table 1. Characteristics of optical filters used for $\mathrm{OH}$ nightglow observations at Ranchi.

\begin{tabular}{lrrr}
\hline Nightglow emission monitored & \multicolumn{3}{c}{ Optical filter deployed } \\
\cline { 2 - 4 } & Central wavelength (nm) & Bandwidth (nm) & Transparency (\%) \\
\hline$P_{1}(2)$ line of $\mathrm{OH}(6,2)$ band & 840.10 & 1.20 & 77 \\
$P_{1}(4)$ line of OH $(6,2)$ band & 846.40 & 1.10 & 85 \\
Background emission at $857 \mathrm{~nm}$ & 856.90 & 2.00 & 86 \\
OH broadband emissions & $705-929$ & 220.0 & 93 \\
\hline
\end{tabular}

$86 \%$. Furthermore, $\mathrm{OH}$ emissions in the wavelength range of $705-929 \mathrm{~nm}$ were monitored using a $200 \mathrm{~nm}$ broadband filter with a transparency of $87 \%$. More details of the filters used for $\mathrm{OH}$ nightglow observations are presented in Table 1. Each emission was monitored for $60 \mathrm{~s}$ and the duration of one complete sequence of six filters was $6 \mathrm{~min}$. Such a choice of exposure time for the $P_{1}(2)$ line, $P_{1}(4)$ line and $857.0 \mathrm{~nm}$ filter is based on the experimental set-up of the Mesospheric Temperature Mapper (MTM) described by Taylor et al. (1999). For these observational settings, the signalto-noise ratio was better than 70 . Nightglow observations were performed in campaigns (each around 13 days centred on the new moon period and under clear sky conditions) during January 2011-March 2011, December 2011-May 2012 and December 2012-March 2013. Overall, around 120 days of good-quality observations were available for meaningful study.

\subsection{Intensity data of $P_{1}(2)$ line, $P_{1}(4)$ line and the background emission}

At $\mathrm{OH}$ emission height, the field of view of the imager was fairly able to cover a $3^{\circ} \times 3^{\circ}$ latitude-longitude grid centred on Ranchi. This region of the image has been considered as the region of interest in the present study. For possible contamination with artificial lights of the city around the airglow site, the image data at further lower elevation were avoided. First, in the image data, five sample locations corresponding to Ranchi (named RNC) and to the vertical projections from the $\mathrm{OH}$ airglow layer to the geographical locations $\pm 1.5^{\circ}$ latitude-longitude north, south, east and west of Ranchi (named NoRNC, SoRNC, EoRNC and WoRNC respectively) were identified within the $3^{\circ} \times 3^{\circ}$ geographical grid. Next, the average intensity of a square bin (centred on each sample location and enclosing a circular field of view of $\sim 4^{\circ}$ ) was estimated for an emission feature. Using this intensity and timestamp information of the associated image and repeating this process for the entire dataset of the emission concerned, the time series for each of the sample locations were generated. Using this technique, the time series of the intensity of $P_{1}(2)$ line, $P_{1}(4)$ line and background emissions for five locations were recorded for further analysis. This process was described in detail in Parihar and Taori (2015). A typical example of such a generated intensity series of $P_{1}(2)$

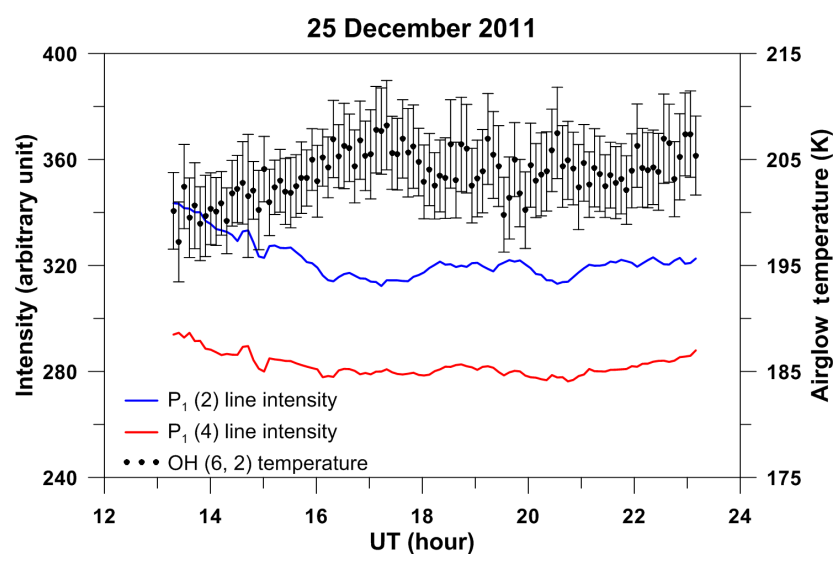

Figure 1. A typical example of the intensity series generated using the image data and airglow temperatures over a geographic spot situated $1.5^{\circ}$ latitude north of Ranchi (named NoRNC) on 25 December 2011 .

line and $P_{1}(4)$ line on 25 December 2011 at location NoRNC (i.e. at $1.5^{\circ}$ latitude north of Ranchi) is shown in Fig. 1. Assuming the temperature dependence of transparency of filters and sensitivity of CCD to be the main sources of the instrumental errors, systematic and random error in the intensity measurements are estimated to be $\sim 8$ and $3 \%$ respectively.

\subsection{OH temperature measurements}

Using the well-known ratio approach suggested by Meinel (1950), OH rotational temperatures (hereafter $T_{\mathrm{OH}}$ ) were derived from the intensity information of $P$ lines of $\mathrm{OH}(6,2)$ Meinel band. The details of the temperature retrieval from the intensity information of the $P_{1}(2)$ and $P_{1}(4)$ lines of the $\mathrm{OH}(6,2)$ band are presented elsewhere (Parihar and Mukherjee, 2008; Parihar et al., 2013). Here, the term values given by Kendall and Clark (1979) and the transition probabilities given by Langhoff et al. (1986) were used in deriving the airglow temperatures. The plot of solid circles in Fig. 1 presents an example of such derived temperature on the particular night of 25 December 2011 at the NoRNC location. Using uncertainty information in the intensity measurements, systematic and random errors in the derived $T_{\mathrm{OH}}$ are estimated to be 4.2 and $2.0 \mathrm{~K}$ respectively. In Fig. 1, the error bars represent this uncertainty in the derived $T_{\mathrm{OH}}$. The 


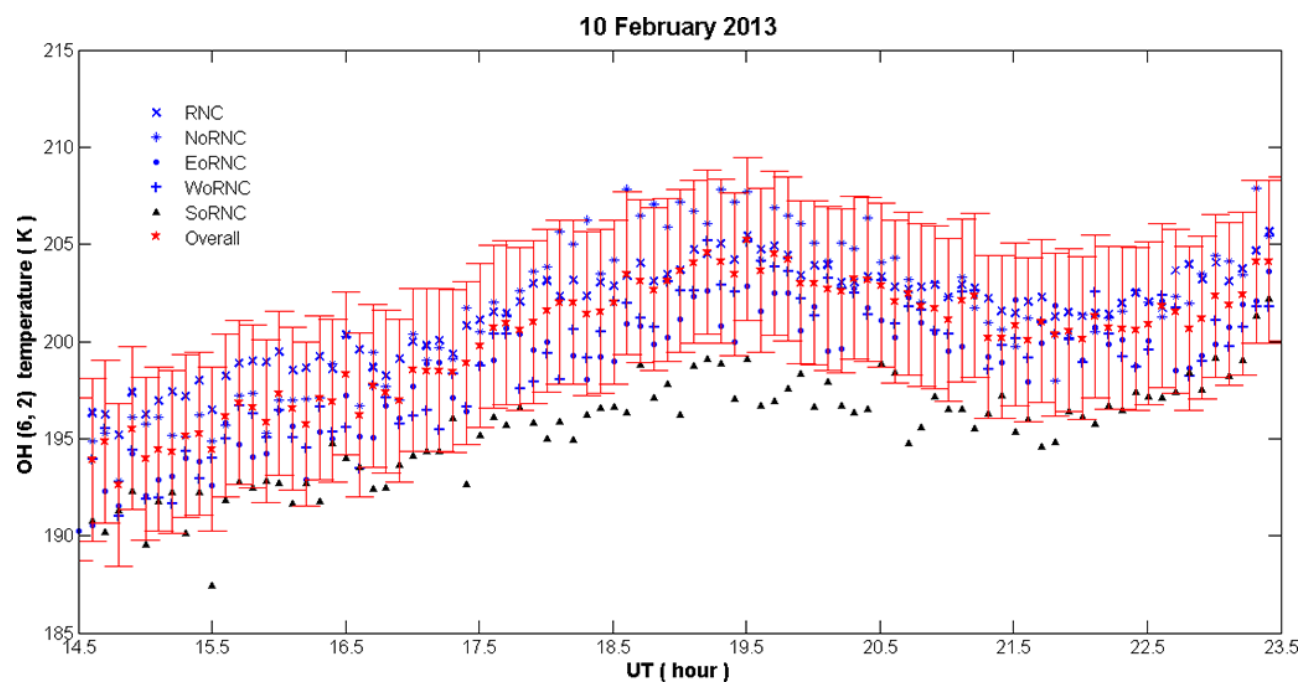

Figure 2. Nocturnal variation of $T_{\mathrm{OH}}$ at different sampling locations on 10 February 2013.

southern edge of imaging observations was often affected by artificial lights from surroundings, and $T_{\mathrm{OH}}$ of SoRNC was discarded for comparison. Figure 2 presents $T_{\mathrm{OH}}$ variation during the night of 10 February 2013 at different sampling locations, wherein the southern edge of images was contaminated. $T_{\mathrm{OH}}$ at contaminated SoRNC was found to be systematically lower than that of other sampling locations. The starred discontinuous plot in Fig. 2 presents the variations in averaged $T_{\mathrm{OH}}$ over all locations (except the contaminated SoRNC). The corresponding error bar denotes the systematic error of $4.2 \mathrm{~K}$ in $T_{\mathrm{OH}}$ measurements.

\section{SABER instrument and $\mathrm{OH}$ equivalent temperature data}

SABER is a 10-channel broadband infrared radiometer on board NASA's TIMED mission satellite that measures earth limb emission (between 1.27 and $16.9 \mu \mathrm{m}$ ) from the lower stratosphere to the lower thermosphere using the limb scanning technique. It was designed to globally explore the energetics, chemistry, dynamics and transport processes of the MLT region on temporal and seasonal timescales. The sounding of the atmosphere by SABER gives vertical scans of limb radiances and their analysis provides information on temperature, pressure, $\mathrm{O}_{3}, \mathrm{H}_{2} \mathrm{O}$ and $\mathrm{CO}_{2}$ mixing ratio, the volume emission rates of $\mathrm{O}_{2}\left({ }^{1} \Delta\right)$ airglow, and $\mathrm{OH}$ airglow with vertical resolution of approximately $2 \mathrm{~km}$ at the tangent point (see http://saber.gats-inc.com). For example, the kinetic temperatures are retrieved from the $\mathrm{CO}_{2}$ emission at $15 \mu \mathrm{m}$ (Mertens et al., 2001). In the present study, the profiles of the kinetic temperature $\left(T_{\mathrm{k}}\right)$ and the volume emission rate (VER) of $\mathrm{OH}$ emissions (at 1.6 and $2.0 \mu \mathrm{m}$ ) of SABER Version 2.0 Level 2A data were used.

\subsection{Coincidences of SABER/TIMED overpasses and airglow measurements}

In principle, the concurrent measurements from the same location should be considered for such comparisons. It is well known that exact coincidences are not possible, spatial coincidence criterion of $\pm 2.5^{\circ}$ latitude-longitude of Ranchi and temporal coincidence criterion of \pm 3 min were defined in the present study. All through 13 campaigns of airglow experiments during 2011-2013, nearly 80 such passes were available in a latitude-longitude grid of $5^{\circ} \times 5^{\circ}$ centred over Ranchi (i.e. in the geographical bin of $20.8-25.8^{\circ} \mathrm{N}$ and $82.5-87.8^{\circ} \mathrm{E}$ ) and were examined. After defining five sample locations, viz. RNC, NoRNC, SoRNC, EoRNC and WoRNC, in a two-dimensional image, this spatial coincidence is further contracted to a $\pm 1.5^{\circ}$ latitude-longitude bin. This matched the SABER's horizontal resolution of $\sim 300 \mathrm{~km}$ along the line of sight (Xu et al., 2006). Complying with this, about 30 coincidences were available for further study. Such a choice of spatial and temporal coincidence is expected to fairly address the limited comparison of two measurements. On 21 nights, such SABER coincidences existed. Sometimes two coincidences in the same day at different locations were also noted.

\subsection{OH-equivalent temperatures from SABER kinetic temperature profiles}

As hydroxyl emissions emanate from an extended altitude regime of $\sim 8-10 \mathrm{~km}$ width centred around $87 \mathrm{~km}$ (Baker et al., 2007; Nikoukar et al., 2007), an approach concerned with OH-equivalent temperature from the SABER kinetic temperature profiles was adopted by several investigators for fair comparison of ground-based and SABER measurements (Oberheide et al., 2006; López-González et al., 2007; Mulli- 


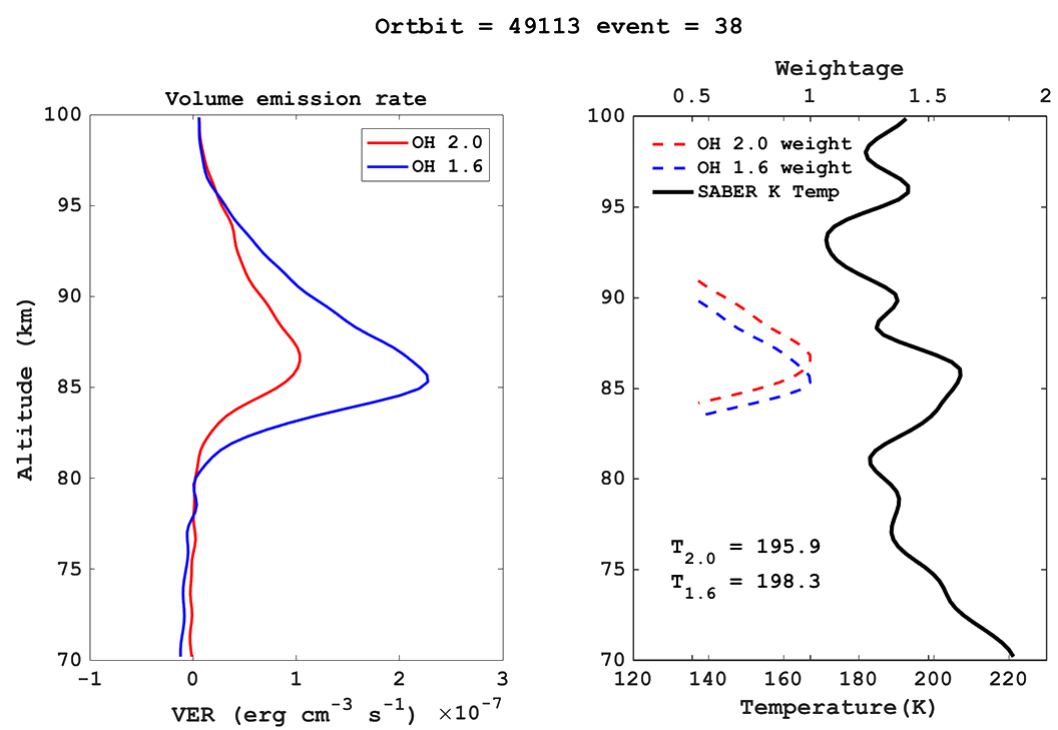

Figure 3. An illustration of estimation of OH-equivalent temperatures from SABER temperature profiles using OH 1.6 and 2.0 $\mu$ m VER profiles as the weighing function. (SABER measurements reference: Orbit 49113 Event 38 of 1 January 2011). The left panel presents OH 1.6 and $2.0 \mu \mathrm{m}$ VER profiles in the blue and red curves respectively. The blue and red broken curves in the right panel symbolize the weighing functions defined using $\mathrm{OH} 1.6$ and $2.0 \mu \mathrm{m}$ VER profiles respectively. SABER temperature profile is shown by a solid curve in right panel.

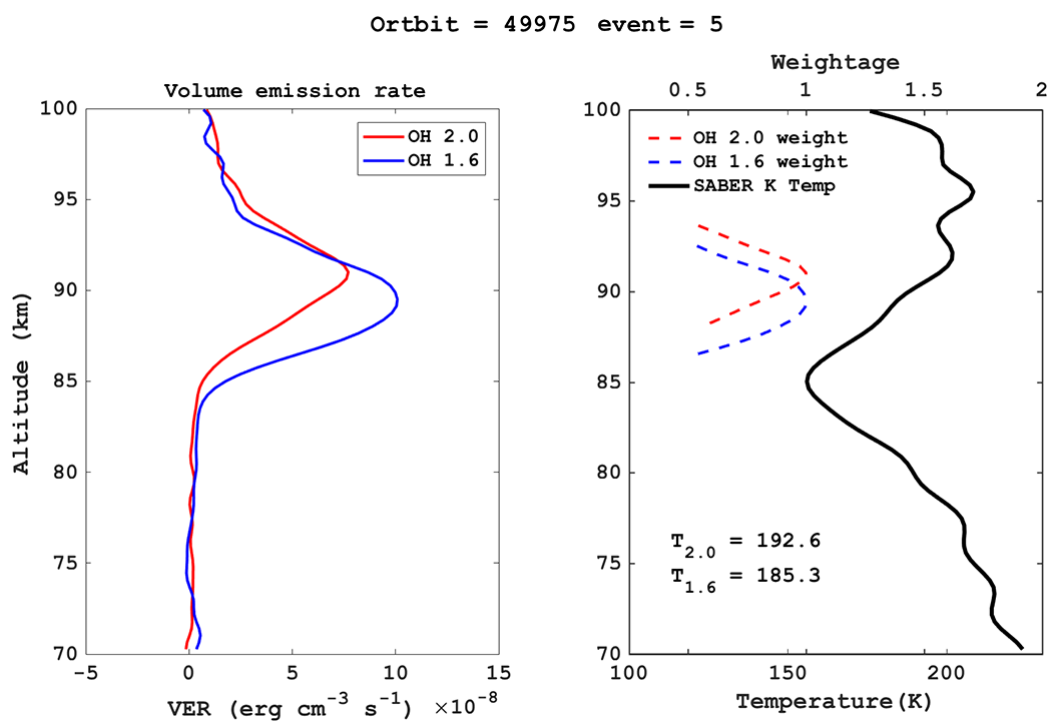

Figure 4. Same as Fig. 2 but for Orbit 49975 Event 05 of 28 February 2011.

gan and Lowe, 2008; French and Mulligan, 2010). This concept is discussed in detail by French and Mulligan (2010). In the present study, two sets of $\mathrm{OH}$-equivalent temperatures were calculated from SABER kinetic temperature profiles using both $\mathrm{OH} 1.6$ and $2.0 \mu \mathrm{m}$ VER profiles as the weighing functions. The weighing functions of two OH VER profiles are based on their corresponding emission peak and full width at half maximum (FWHM). Figures 3 and 4 present an illustration of the estimation of OH-equivalent temperatures for Orbit 49113 Event 38 of 1 January and Orbit 49975 Event 05 of 28 February 2011 respectively. Two OH
VER profiles are plotted in the left panel, and two broken curves in the right panel show the weighing functions. The kinetic temperature profile is shown by the solid curve in the right panel. OH-equivalent temperatures determined using $\mathrm{OH} 1.6$ and $2.0 \mu \mathrm{m}$ VER profiles as the weighing functions are named as $T_{1.6}$ and $T_{2.0}$ respectively. From Orbit 49975 Event $05, T_{1.6}$ and $T_{2.0}$ are estimated to be $\sim 185.3$ and $192.6 \mathrm{~K}$ respectively. A difference of $\sim 7 \mathrm{~K}$ can be noted between two temperatures and is expected due to the difference in their peak emission heights. SABER $2.0 \mu \mathrm{m}$ channel primarily accepts emissions from $\mathrm{OH}(9,7)$ and $(8,6)$ bands, 


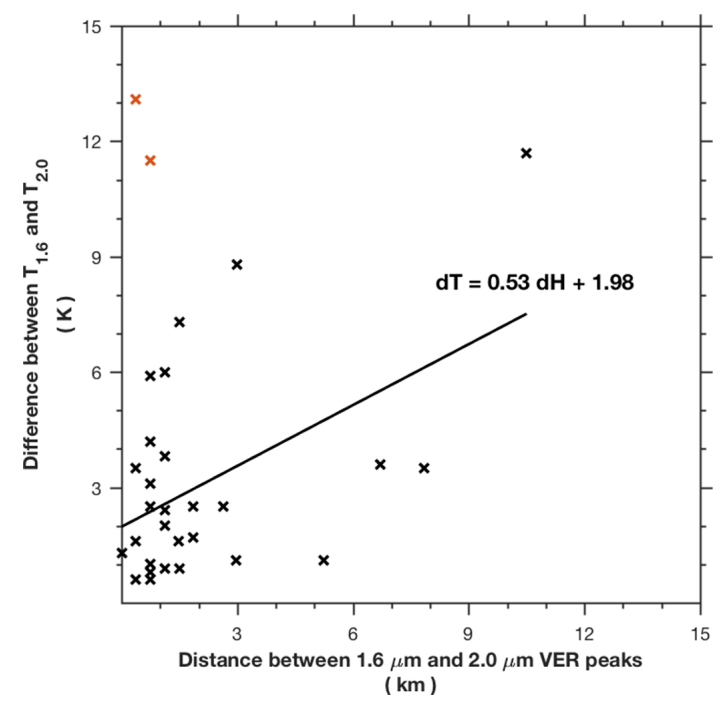

Figure 5. Scatter plot showing the dependence of the difference of $T_{1.6}$ and $T_{2.0} \mathrm{OH}$-equivalent temperatures on the separation of 1.6 and $2.0 \mu \mathrm{m}$ VER peaks.

while $\mathrm{OH}(5,3)$ and $(4,2)$ band emissions are mainly collected at $1.6 \mu \mathrm{m}$ (Baker et al., 2007). As $\mathrm{OH}$ emissions from different $v^{\prime}$ peak at different heights (von Savigny, 2015; Noll et al., 2016), the difference in $\mathrm{OH} 2.0$ and $1.6 \mu \mathrm{m}$ emission peaks is observed. Generally, the $2.0 \mu \mathrm{m}$ emission peak lies above that of the $1.6 \mu \mathrm{m}$ channel by $\sim 1.6 \mathrm{~km}$ at about $89 \pm 2 \mathrm{~km}$, thereby resulting in different values of two $\mathrm{OH}-$ equivalent temperatures. In about $20 \%$ of the events, the difference was about $1 \mathrm{~K}$ or less and $4 \mathrm{~K}$ or less in about $53 \%$ of the events. Sometimes differences as high as $11-13 \mathrm{~K}$ were also noted. Figure 5 presents the scatter plot of the separation of 1.6 and 2.0 $\mu \mathrm{m}$ VER peaks and the difference of two $\mathrm{OH}$-equivalent temperatures. Note that two data values (marked in red) show large temperature differences even for small separation of two emission peaks, and are thus considered as outliers. Barring two exceptions, a linear fit was applied to the scatter plot and indicates a marginal linear dependence of the temperature difference of $T_{1.6}$ and $T_{2.0}$ on the separation of their peaks with a Pearson correlation coefficient of $\sim 0.49$. Also, the FWHM thickness of both profiles was generally $8 \pm 2 \mathrm{~km}$. OH-equivalent temperature estimated using a SABER kinetic temperature profile strongly depends upon the choice of weighing function used. French and Mulligan (2010) estimated OH-equivalent temperatures using different weighing functions and found a maximum difference of $3 \mathrm{~K}$ among the different selections considered. Herein, $\mathrm{OH}$-equivalent temperatures were also determined using another type of weighing function - a Gaussian fitted to SABER's OH VER profiles (based on French and Mulligan, 2010); however, the disparity between the ground-based and satellite measurements was found to increase further. Hence, $T_{1.6}$ and $T_{2.0}$ determined using OH VER weighting was con-

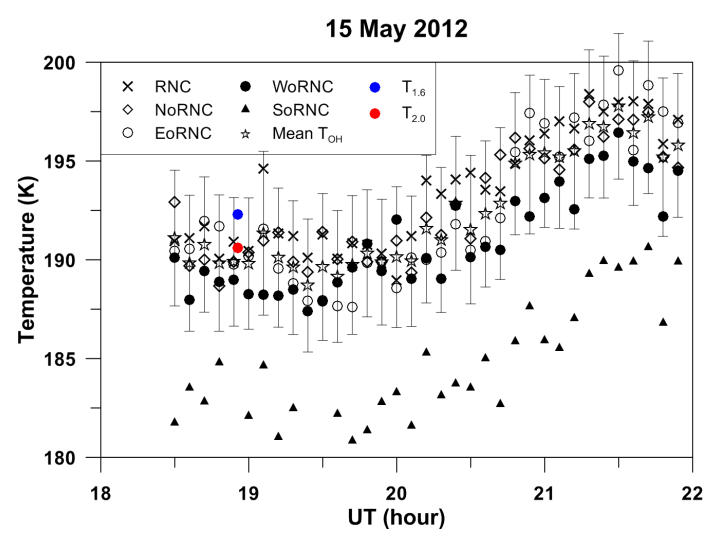

Figure 6. A comparison of ground-based $\mathrm{OH}$ temperature and SABER measurements on 15 May 2012. The variation of $T_{\mathrm{OH}}$ at RNC, NoRNC, EoRNC, WoRNC, SoRNC and overall mean (excluding the contaminated SoRNC) are presented by “ $\times$ ", “ $\diamond "$, " ○”,

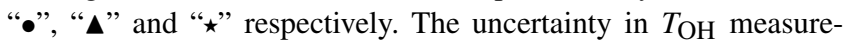
ments is shown by error bars across mean $T_{\mathrm{OH}}$ values. Solid circles in blue and red represent SABER OH-equivalent temperatures $T_{1.6}$ and $T_{2.0}$ respectively.

sidered for comparison. Remsberg et al. (2008) reported random and systematic errors of 2.2 and $3.8 \mathrm{~K}$ respectively in SABER temperatures for the data version 1.07.

\section{Results and discussions}

Some examples of the comparison of ground-based $\mathrm{OH}$ temperatures with SABER measurements are shown in Figs. 6 and 7. Ground-based $T_{\mathrm{OH}}$ measurements at RNC, NoRNC, EoRNC, WoRNC, SoRNC and overall mean (excluding the contaminated SoRNC) are presented in black, while SABER measurements are marked in colour. The uncertainty in $T_{\mathrm{OH}}$ measurements are shown by error bars across mean $T_{\mathrm{OH}}$ values. SABER measurements, viz. $T_{1.6}$ and $T_{2.0}$, are denoted by solid circles in blue and red respectively. Again, $T_{\mathrm{OH}}$ measurements at contaminated SoRNC can be observed to be systematically lower than other measurements. Good agreement between $T_{\mathrm{OH}}$ and SABER OH-equivalent temperatures can be seen on 15 May 2012 and 11 March 2013, while a large difference of about $20 \mathrm{~K}$ can be noted between two measurements on 13 February 2013. Table 2 summarizes coincidental SABER and $T_{\mathrm{OH}}$ measurements along with the difference observed between two measurements. The difference can mostly be seen to lie in the range of $0-15 \mathrm{~K}$. A difference as high as $32 \mathrm{~K}$ is also noted on 22 May 2012. Sometimes the horizontal field of view of the SABER instrument subsumed two or more of the sampling locations; however, agreement improved between two measurements in general as SABER approached Ranchi. In Fig. 7b, the encircled SABER overpass is closer to RNC than the other one and is observed to be in good agreement with $T_{\mathrm{OH}}$. 


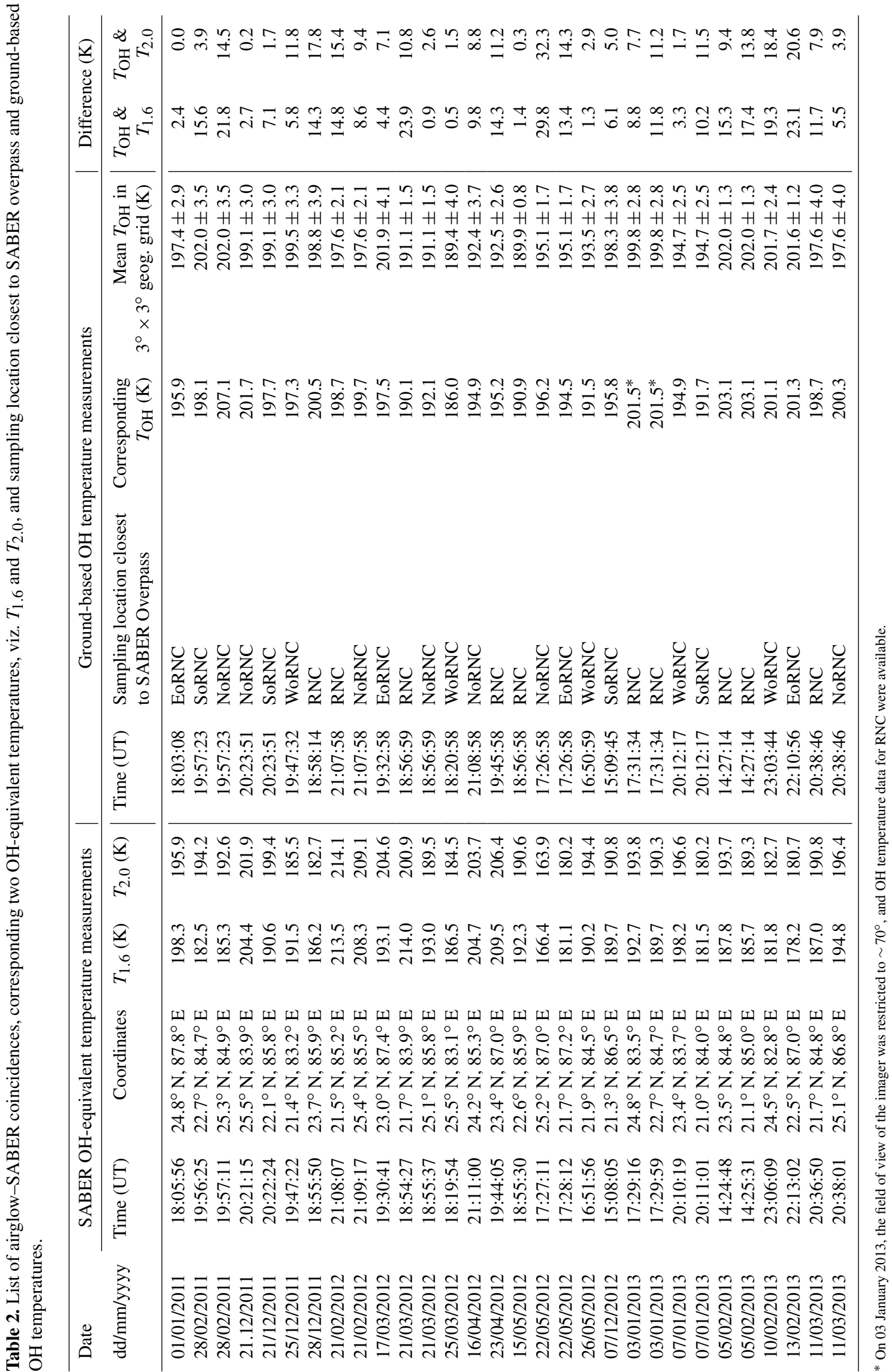



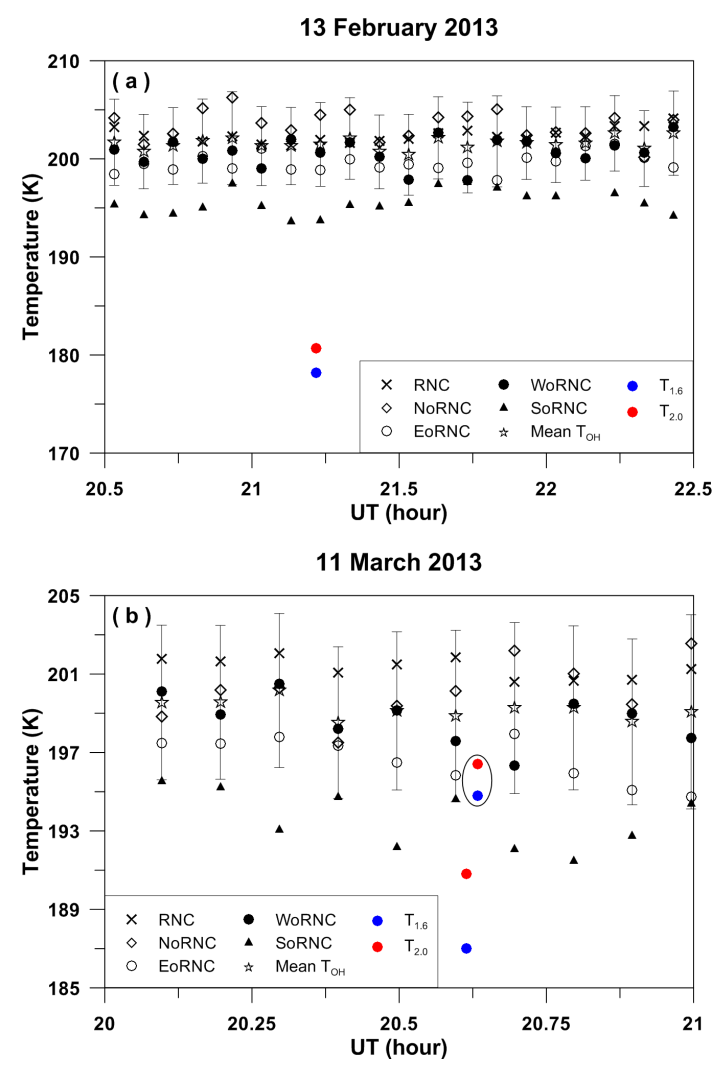

Figure 7. Same as Fig. 6 but for 13 February and 11 March 2013.

Usually the difference of $T_{\mathrm{OH}}$ at different sampling locations varied between 2 and $7 \mathrm{~K}$ for coincidental events reported herein. Assuming that $T_{\mathrm{OH}}$ measurements at RNC, NoRNC, EoRNC, WoRNC and SoRNC characterize the range of temperature variation over a $3^{\circ} \times 3^{\circ}$ latitudelongitude grid over Ranchi, individual comparison of $T_{\mathrm{OH}}$ measurements with $T_{1.6}$ and $T_{2.0}$ was carried out; see Fig. 8 . In Fig. 8, (i) coincidental SABER Orbit number and temperature measurements are shown on the $x$ axis and $y$ axis respectively (ii) the minimum and maximum of $T_{\mathrm{OH}}$ measurements at RNC, NoRNC, EoRNC, WoRNC, and SoRNC are represented by open symbols and (iii) SABER OH-equivalent temperatures are shown by solid circles. The black and purple error bars are maximum uncertainty in $T_{\mathrm{OH}}$ and SABER measurements respectively. A good agreement between $T_{\mathrm{OH}}$ and SABER measurements can be seen within the limits of experimental uncertainties. Considering the uncertainty in each temperature measurement, the difference of $T_{\mathrm{OH}}$ and SABER measurements was analysed at steps of $4 \mathrm{~K}$; see Fig. 9. The difference of $T_{\mathrm{OH}}$ and $T_{1.6}$ is shown by a blue histogram, while that of $T_{\mathrm{OH}}$ and $T_{2.0}$ is presented by a red one. Clearly $T_{\mathrm{OH}}$ can be seen to match better with $T_{2.0}$ than with $T_{1.6}$. In about $37 \%$ of cases, fair agreement between $T_{\mathrm{OH}}$ and $T_{2.0}$ can be noted within the limits of experimental uncertainty of about $5.6 \mathrm{~K}$ (the combined systematic error of $T_{\mathrm{OH}}$ and SABER measurements), and indicates that the matching of two measurements is within an acceptable range of their combined systematic error. A difference of 7-12 $\mathrm{K}$ between $T_{\mathrm{OH}}$ and $T_{2.0}$ was observed in a large number of remaining coincidences. Scheer et al. (2006) reported the difference of $0.2-11.5 \mathrm{~K}$ between the ground-based $T_{\mathrm{OH}}$ and CRISTA temperatures. As a trial, $\mathrm{OH}$-equivalent temperatures were calculated using an intermediate weighing function, viz. the average of $\mathrm{OH} 1.6$ and $2.0 \mu \mathrm{m}$ VER profiles, and compared it with $T_{\mathrm{OH}}$ measurements. However, the difference between two measurements was found to increase further.

Some of these cases are of interest in the context of a report on SABER kinetic temperature errors by García-Comas et al. (2008). In the presence of large vertical gradient in temperature, which may be produced by tidal influence, inversion layers or other phenomenon, the temperatures derived using non-LTE (local thermodynamic equilibrium) algorithms are highly sensitive to uncertainty in collisional rates. These errors will be more dominant in the region of a large temperature gradient. García-Comas et al. (2008) estimated the maximum error of $\pm 8 \mathrm{~K}$ in SABER temperature at around $90 \mathrm{~km}$, especially near the crest and trough of the temperature inversion, for a typical case in such a situation. A similar scenario was noted in several events reported herein, and Fig. 10 presents a few examples of such cases. On 21 February 2012, a strong temperature inversion of more than $35 \mathrm{~K}$ was seen in SABER kinetic temperature profiles in the $83-88 \mathrm{~km}$ region. Near the vicinity of this inversion crest (about $88 \mathrm{~km}$ ), a peak of OH $2.0 \mu$ VER can be noted. As such, errors in estimated $\mathrm{OH}$-equivalent temperature are expected for the reasons pointed out by GarcíaComas et al. (2008). This possibly resulted in the large difference of $8-16 \mathrm{~K}$ between the two measurements for this coincidence. This difference lessened as the separation between the crest of inversion and $\mathrm{OH}$ peak increased (as can be seen for 17 March 2012). Generally, $T_{\mathrm{OH}}$ was found to be lower than SABER OH-equivalent temperature whenever the temperature inversion existed and the $\mathrm{OH}$ emission peak lay in close proximity to its crest. In such cases, the $\mathrm{OH}$ layer generally lay around or below $89 \mathrm{~km}$. A similar discrepancy between two measurements was noted during the presence of strong tides as well.

Overall, the mean values of $T_{\mathrm{OH}}, T_{1.6}$ and $T_{2.0}$ were $197.3 \pm 4.6,192.0 \pm 10.8$ and $192.7 \pm 10.3 \mathrm{~K}$ respectively. The ground-based temperatures were $4-5 \mathrm{~K}$ higher than SABER values, similar to earlier reports (von Savigny et al., 2004; Oberheide et al., 2006; Scheer et al., 2006; LópezGonzález et al., 2007; Mulligan and Lowe, 2008). As $T_{\mathrm{OH}}$ derived from Meinel band line intensities strongly depend on the choice of transition probabilities (French et al., 2000), $T_{\mathrm{OH}}$ were also derived using the transition probabilities given by Mies (1974), Turnbull and Lowe (1989) and Goldman (1998); however, the mean difference between $T_{\mathrm{OH}}$ and SABER measurements increased from 3 to $15 \mathrm{~K}$ with their use. The $T_{\mathrm{OH}}$ derived using Mies (1974) and Goldman (1998) were in general 8-9 K warmer than SABER measurements. 


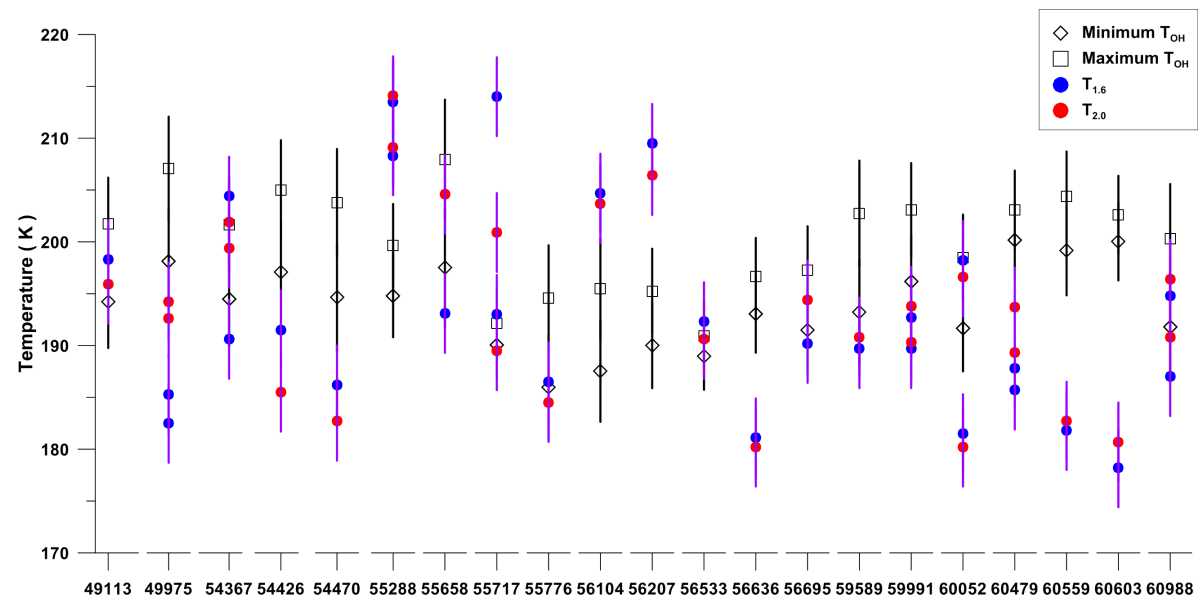

Figure 8. Plots showing limits of $T_{\mathrm{OH}}$ variation in a $3^{\circ} \times 3^{\circ}$ latitude-longitude grid over Ranchi for coincidental events and comparison with $T_{1.6}$ and $T_{2.0}$ measurements.

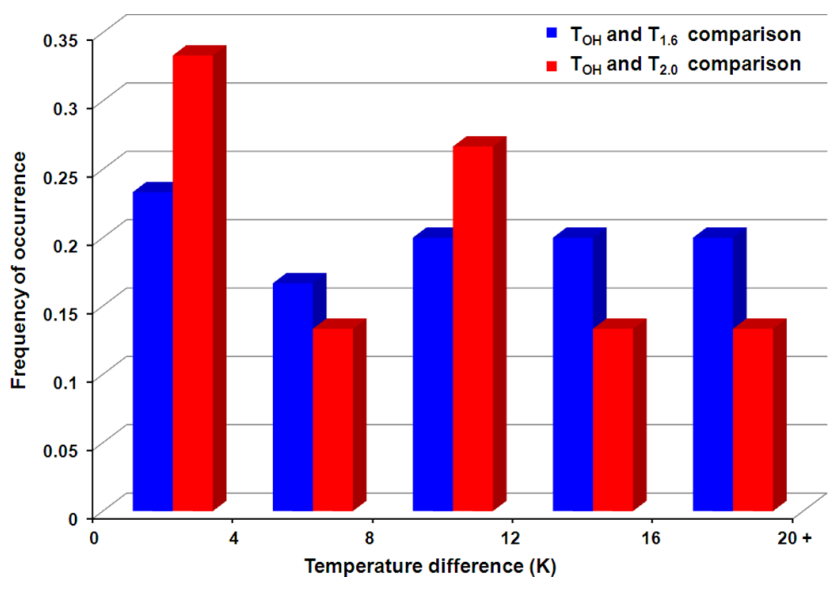

Figure 9. Histograms showing the frequency of coincidental cases against the observed difference of ground-based $T_{\mathrm{OH}}$ measurements and SABER OH-equivalent temperatures $\left(T_{1.6}\right.$ and $\left.T_{2.0}\right)$ at steps of $4 \mathrm{~K}$.

A difference of about $15 \mathrm{~K}$ was noted between $T_{\mathrm{OH}}$ derived using transition probabilities given by Turnbull and Lowe (1989) and SABER measurements.

\section{Conclusions}

A limited comparison of the ground-based measurements of hydroxyl temperatures around the mesopause region were made with the $\mathrm{OH}$-equivalent temperatures retrieved from SABER on-board TIMED observations of 30 coincidences. The results of comparison are very encouraging in the sense that the ground-based temperatures derived using the transition probabilities given by Langhoff et al. (1986) are in good agreement with the satellite retrievals, within the limits of experimental errors. Similar to earlier reports (von Savigny
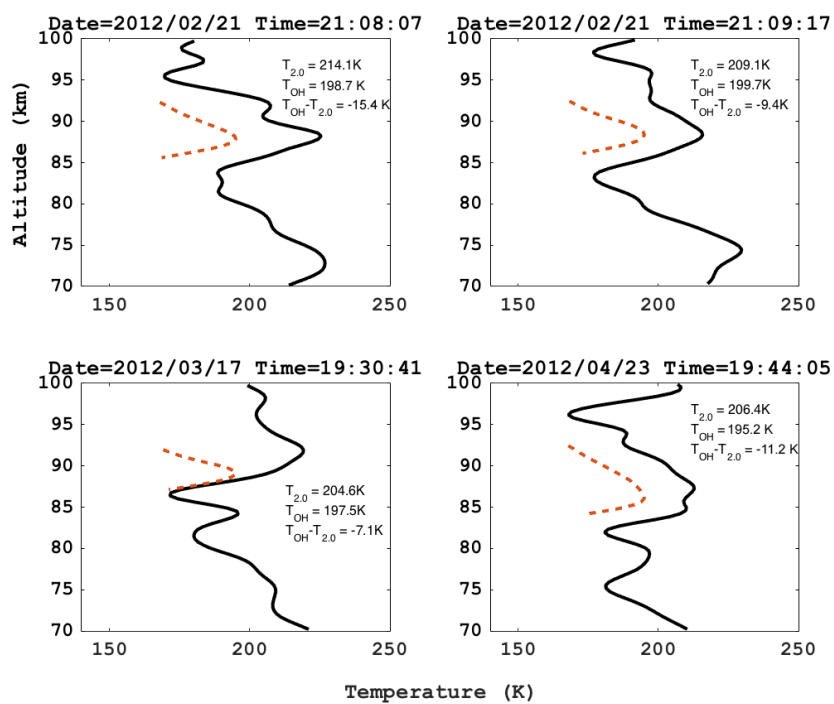

Figure 10. Typical examples of SABER kinetic temperature profiles marked by strong inversions and nearly co-located $\mathrm{OH}$ layer. In each plot, the temperature measurements are shown by solid curves, while the broken curve symbolizes the $\mathrm{OH}$ 2.0 $\mu$ VER over FWHM.

et al., 2004; Oberheide et al., 2006; López-González et al., 2007; Mulligan and Lowe, 2008), OH ground-based temperatures are found to be warmer than SABER measurements by $4-5 \mathrm{~K}$ on average in this present study. This study also indicates that the difference between two measurements is large ( $8 \mathrm{~K}$ or more) in cases when $\mathrm{OH}$ layer lay in the vicinity of large temperature inversions. $T_{\mathrm{OH}}$ was found to be closer to $T_{2.0}$ in comparison to $T_{1.6}$. In the future, efforts will be made to perform such a study with a longer dataset of ground-based $\mathrm{OH}$ temperature measurements. 


\section{Data availability}

The $\mathrm{OH}$ temperature data used in this study are available upon request from Navin Parihar (email: navindeparihar@gmail.com).

Competing interests. The authors declare that they have no conflict of interest.

Acknowledgements. Funds for airglow research at the Indian Institute of Geomagnetism provided by the Department of Science and Technology (DST), Government of India, New Delhi, and SABER/TIMED data obtained from http://saber.gats-inc.com are gratefully acknowledged. NP is thankful to the International Centre for Theoretical Physics for the award of Junior-Associateship. The authors are grateful to the reviewers for their invaluable suggestions.

The topical editor, C. Jacobi, thanks the two anonymous referees for help in evaluating this paper.

\section{References}

Baker, D. J., Thurgood, B. K., Harrison W. K., Mlynczak, M. G., and Russell, J. M.: Equatorial enhancement of the nighttime $\mathrm{OH}$ mesospheric infrared airglow, Phys. Scripta, 75, 615-619, 2007.

Bittner, M., Offermann, D., Graef, H.-H., Donner, M., and Hamilton, K.: An 18-year time series of $\mathrm{OH}$ rotational temperatures and middle atmosphere decadal variations, J. Atmos. Sol.-Terr. Phy., 64, 1147-1166, 2002.

Brasseur, G. and Solomon, S.: Aeronomy of the middle atmosphere: Chemistry and physics of the stratosphere and mesosphere, D. Reidel Publishing Co., Dordrecht, the Netherlands, 1984.

Burns, G. B., Kawahara, T. D., French, W. J. R., Nomura, A., and Klekociuk, A. R.: A comparison of hydroxyl rotational temperatures from Davis $\left(69^{\circ} \mathrm{S}, 78^{\circ} \mathrm{E}\right)$ with sodium lidar temperatures from Syowa $\left(69^{\circ} \mathrm{S}, 39^{\circ} \mathrm{E}\right)$, Geophys. Res. Lett., 30, 1025 , doi:10.1029/2002GL016413, 2003.

French, W. J. R. and Mulligan, F. J.: Stability of temperatures from TIMED/SABER v1.07 (2002-2009) and Aura/MLS v2.2 (2004-2009) compared with OH(6-2) temperatures observed at Davis Station, Antarctica, Atmos. Chem. Phys., 10, 1143911446, doi:10.5194/acp-10-11439-2010, 2010.

French, W. J. R., Burns, G. B., Finlayson, K., Greet, P. A., Lowe, R. P., and Williams, P. F. B.: Hydroxyl (6-2) airglow emission intensity ratios for rotational temperature determination, Ann. Geophys., 18, 1293-1303, doi:10.1007/s00585-000-1293-2, 2000.

García-Comas, M., López-Puertas, M., Marshall, B. T., Wintersteiner, P. P., Funke, B., Bermejo-Pantaleón, D., Mertens, C. J., Remsberg, E. E., Gordley, L. L., Mlynczak, M. G., and Russell, J. M.: Errors in Sounding of the Atmosphere using Broadband Emission Radiometry (SABER) kinetic temperature caused by non-local-thermodynamic-equilibrium model parameters, J. Geophys. Res., 113, D24106, doi:10.1029/2008JD010105, 2008.

García-Comas, M., Funke, B., López-Puertas, M., BermejoPantaleón, D., Glatthor, N., von Clarmann, T., Stiller, G., Grabowski, U., Boone, C. D., French, W. J. R., Leblanc, T.,
López-González, M. J., and Schwartz, M. J.: On the quality of MIPAS kinetic temperature in the middle atmosphere, Atmos. Chem. Phys., 12, 6009-6039, doi:10.5194/acp-12-6009-2012, 2012.

García-Comas, M., Funke, B., Gardini, A., López-Puertas, M., Jurado-Navarro, A., von Clarmann, T., Stiller, G., Kiefer, M., Boone, C. D., Leblanc, T., Marshall, B. T., Schwartz, M. J., and Sheese, P. E.: MIPAS temperature from the stratosphere to the lower thermosphere: Comparison of vM21 with ACE-FTS, MLS, OSIRIS, SABER, SOFIE and lidar measurements, Atmos. Meas. Tech., 7, 3633-3651, doi:10.5194/amt-7-3633-2014, 2014.

Goldman, A., Schoenfeld, W. G., Goorvitch, D., Chackerian, C., Dothe, H., Melen, F., Abrams, M. C., and Selby, J. E. A.: Updated line parameters for $\mathrm{OH} X^{2} \Pi-X^{2} \Pi\left(v^{\prime \prime}, v^{\prime}\right)$ transitions, J. Quant. Spectrosc. Ra., 59, 453-469, 1998.

Greet, P. A., French, W. J. R., Burns, G. B., Williams, P. F. B., Lowe, R. P., and Finlayson, K.: OH(6-2) spectra and rotational temperature measurements at Davis, Antarctica, Ann. Geophys., 16, 77-89, doi:10.1007/s00585-997-0077-3, 1998.

Kendall, D. J. W. and Clark, T. A.: The pure rotational atmospheric lines of hydroxyl, J. Quant. Spectrosc. Ra., 21, 511-518, 1979.

Langhoff, S. R., Werner, H. J., and Rosmus, P.: Theoretical transition probabilities for the OH Meinel system, J. Mol. Spectrosc., 118, 507-529, 1986.

López-González, M. J., García-Comas, M., Rodríguez, E., LópezPuertas, M., Shepherd, M. G., Shepherd, G. G., Sargoytchev, S., Aushev, V. M., Smith, S. M., Mlynczak, M. G., Russell, J. M., Brown, S., Cho, Y.-M., and Wiens, R. H.: Groundbased mesospheric temperatures at mid-latitude derived from $\mathrm{O}_{2}$ and $\mathrm{OH}$ airglow SATI data: Comparison with SABER measurements, J. Atmos. Sol.-Terr. Phy., 69, 17-18, 2379-2390, doi:10.1016/j.jastp.2007.07.004, 2007.

Meinel, A. B.: OH Emission Bands in the Spectrum of the Night Sky II, Astrophys. J., 112, 120-130, 1950.

Meriwether, J. W.: High latitude airglow observations of correlated short-term fluctuations in the hydroxyl meinel (8-3) band intensity and rotational temperature, Planet. Space Sci., 23, 12111221, 1975.

Mertens, C. J., Mlynczak, M. G., López-Puertas, M., Wintersteiner, P. P., Picard, R. H., Winick, J. R., Gordley, L. L., and Russell, J. M.: Retrieval of mesospheric and lower thermospheric kinetic temperature from measurements of $\mathrm{CO}_{2} 15 \mu \mathrm{m}$ Earth Limb Emission under non-LTE conditions, Geophys. Res. Lett., 28, 1391-1394, doi:10.1029/2000GL012189, 2001.

Mies, F. H.: Calculated vibrational transition probabilities of $\mathrm{OH}\left(X^{2} \Pi\right)$, J. Mol. Spectrosc., 53, 150-188, 1974.

Mlynczak, M. G.: Energetics of the mesosphere and lower thermosphere and the SABER experiment, Adv. Space Res., 20, 11771183, doi:10.1016/S0273-1177(97)00769-2, 1997.

Mlynczak, M. G. and Solomon, S.: A detailed evaluation of the heating efficiency in the middle atmosphere, J. Geophys. Res., 98, 10517-10541, doi:10.1029/93JD00315, 1993.

Mukherjee, G. K. and Parihar, N.: Measurement of rotational temperature at Kolhapur, India, Ann. Geophys., 22, 3315-3321, doi:10.5194/angeo-22-3315-2004, 2004.

Mulligan, F. J. and Lowe, R. P.: OH-equivalent temperatures derived from ACE-FTS and SABER temperature profiles - a comparison with $\mathrm{OH}^{*}(3-1)$ temperatures from Maynooth $\left(53.2^{\circ} \mathrm{N}, 6.4^{\circ} \mathrm{W}\right)$, 
Ann. Geophys., 26, 795-811, doi:10.5194/angeo-26-795-2008, 2008.

Nikoukar, R., Swenson, G. R., Liu, A. Z., and Kamalabadi, F.: On the variability of mesospheric $\mathrm{OH}$ emission profiles, J. Geophys. Res., 112, D19109, doi:10.1029/2007JD008601, 2007.

Noll, S., Kausch, W., Kimeswenger, S., Unterguggenberger, S., and Jones, A. M.: Comparison of VLT/X-shooter $\mathrm{OH}$ and $\mathrm{O}_{2}$ rotational temperatures with consideration of TIMED/SABER emission and temperature profiles, Atmos. Chem. Phys., 16, 50215042, doi:10.5194/acp-16-5021-2016, 2016.

Oberheide, J., Offermann, D., Russell III, J. M., and Mlynczak, M. G.: Intercomparison of kinetic temperature from $15 \mu \mathrm{m} \mathrm{CO}_{2}$ limb emissions and $\mathrm{OH}^{*}(3,1)$ rotational temperature in nearly coincident air masses: SABER, GRIPS, Geophys. Res. Lett., 33, L14811, doi:10.1029/2006GL026439, 2006.

Offermann, D. and Gerndt, R.: Upper mesosphere temperatures from $\mathrm{OH}^{*}$ emissions, Adv. Space Res., 10, 217-221, 1990.

Offermann, D., Hoffmann, P., Knieling, P., Koppmann, R., Oberheide, J., and Steinbrecht, W.: Long-term trends and solar cycle variations of mesospheric temperature and dynamics, J. Geophys. Res., 115, D18127, doi:10.1029/2009JD013363, 2010.

Parihar, N. and Mukherjee, G. K.: Measurement of mesopause temperature from hydroxyl nightglow at Kolhapur $\left(16.8^{\circ} \mathrm{N}\right.$, 74.2 E), India, Adv. Space Res., 41, 660-669, 2008.

Parihar, N. and Taori, A.: An investigation of long-distance propagation of gravity waves under CAWSES India Phase II Programme, Ann. Geophys., 33, 547-560, doi:10.5194/angeo-33547-2015, 2015.

Parihar, N., Taori, A., Gurubaran, S., and Mukherjee, G. K.: Simultaneous measurement of OI $557.7 \mathrm{~nm}, \mathrm{O}_{2}(0,1)$ Atmospheric Band and $\mathrm{OH}(6,2)$ Meinel Band nightglow at Kolhapur $\left(17^{\circ} \mathrm{N}\right)$, India, Ann. Geophys., 31, 197-208, doi:10.5194/angeo-31-1972013, 2013.

Remsberg, E. E., Marshall, B. T., Garcia-Comas, M., Krueger, D., Lingenfelser, G. S., Martin-Torres, J., Mlynczak, M. G., Russell, J. M., Smith, A. K., Zhao, Y., Brown, C., Gordley, L. L., Lopez-Gonzalez, M. J., Lopez-Puertas, M., She, C.-Y., Taylor, M. J., and Thompson, R. E.: Assessment of the quality of the Version 1.07 temperature-versus-pressure profiles of the middle atmosphere from TIMED/SABER, J. Geophys. Res., 113, 21562202, doi:10.1029/2008JD010013, 2008.

Scheer, J. and Reisin, E. R.: Rotational temperatures for $\mathrm{OH}$ and $\mathrm{O}_{2}$ airglow bands measured simultaneously from El Leoncito ( $31^{\circ} 48^{\prime}$ S), J. Atmos. Terr. Phys., 52, 47-57, 1990.

Scheer, J., Reisin, E. R., Gusev, O. A., French, W. J. R., Hernandez, G., Huppi, R., Ammosov, P., Gravilyeva, G. A., and Offermann, D.: Use of CRISTA mesopause region temperatures for the intercalibration of ground-based instruments, J. Atmos. Sol.-Terr. Phy., 68, 1698-1708, doi:10.1016/j.jastp.2005.12.009, 2006.
Sheese, P. E., Llewellyn, E. J., Gattinger, R. L., Bourassa, A. E., Degenstein, D. A., Lloyd, N. D., and McDade, I. C.: Mesopause temperatures during the polar mesospheric cloud season, Geophys. Res. Lett., 38, L11803, doi:10.1029/2011GL047437, 2011.

Smith, A. K.: Physics and chemistry of the mesopause region, J. Atmos. Sol.-Terr. Phy., 66, 839-857, doi:10.1016/j.jastp.2004.01.032, 2004.

Takahashi, H., Clemesha, B. R., Sahai, Y., and Batista, P. P.: Seasonal variations of the mesopause temperature observed at equatorial $\left(4^{\circ} \mathrm{S}\right)$ and low $\left(23^{\circ} \mathrm{S}\right)$ latitude stations, Adv. Space Res., 14, 97-100, 1994.

Taylor, M. J., Pendleton, W. R., Jr., Gardner, C. S., and States, R. J.: Comparison of terdiurnal tidal oscillations in mesospheric $\mathrm{OH}$ rotational temperature and $\mathrm{Na}$ lidar temperature measurements at mid-latitudes for fall/spring conditions, Earth Planets Space, 51, 877-885, 1999.

Turnbull, D. N. and Lowe, R. P.: New hydroxyl transition probabilities and their importance in airglow studies, Planet. Space Sci., 37, 723-738, 1989.

von Savigny, C.: Variability of $\mathrm{OH}(3-1)$ emission altitude from 2003 to 2011: Long-term stability and universality of the emission rate-altitude relationship, J. Atmos. Sol.-Terr. Phy., 127, 120-128, doi:10.1016/j.jastp.2015.02.001, 2015.

von Savigny, C., Eichmann, K.-U., Llewellyn, E. J., Bovensmann, H., Burrows, J. P., Bittner, M., Höppner, K., Offermann, D., Taylor, M. J., Zhao, Y., Steinbrecht, W., and Winkler, P.: First nearglobal retrievals of $\mathrm{OH}$ rotational temperatures from satellitebased Meinel band emission measurements, Geophys. Res. Lett., 31, L15111, doi:10.1029/2004GL020410, 2004.

Xu, J., She, C. Y., Yuan, W., Mertens, C. J., Mlynczak, M. G., and Russell, J. M.: Comparison between the temperature measurements by TIMED/SABER and lidar in the midlatitude, J. Geophys. Res., 111, A10S09, doi:10.1029/2005JA011439, 2006.

Xu, J., Liu, H.-L., Yuan, W., Smith, A. K., Roble, R. G., Mertens, C. J., Russell, J. M., and Mlynczak, M. G.: Mesopause structure from Thermosphere, Ionosphere, Mesosphere, Energetics, and Dynamics (TIMED)/Sounding of the Atmosphere Using Broadband Emission Radiometry (SABER) observations, J. Geophys. Res., 112, D09102, doi:10.1029/2006JD007711, 2007. 